\title{
Potentially inappropriate prescribing to older patients receiving multidose drug dispensing
}

\author{
Anette Vik Josendal ${ }^{1,2^{*}}$ (D), Trine Strand Bergmo ${ }^{1}$ and Anne Gerd Granas ${ }^{1,2}$ (D)
}

\begin{abstract}
Background: Multidose drug dispensing (MDD) is an adherence aid that provides patients with machine-dispensed medicines in disposable unit bags, usually for a 14 day period. Previous studies have suggested that the quality of prescribing, with time, is lower for MDD users, compared to patients receiving prescriptions dispensed as usual. This study aimed to examine the quality of prescribing to Norwegian elderly home care service patients receiving MDD.

Methods: A cross-sectional study comprising 45,593 MDD patients aged $\geq 70$ years was performed. The proportion of potentially inappropriate medications (PIMs) was assessed using the Norwegian General Practice Criteria, and drug-drug interactions (DDI) were investigated using the Norwegian Medicines Agency database.

Results: On average, patients were prescribed 10.6 drugs ( $S D=5.0)$, of which 6.1 were dispensed via MDD. Men used on average fewer drugs than women (10.7 vs 11.1), Twenty-seven percent of patients used at least one PIM. Concomitant use of three or more psychotropic drugs (10.8\%), and prescribing of diazepam (6.4\%) was the most commonly identified inappropriate prescribing. DDIs affected $59 \%$ of the patients, however, only $2.7 \%$ had serious interactions. Women were more frequently exposed to both PIMs and DDIs than men, with an odds ratio of 1.50 (95\% Cl: $1.43-1.58)$ and 1.43 (95\% Cl: 1.37-1.50), respectively.
\end{abstract}

Conclusions: Polypharmacy is common in elderly Norwegian patients using MDD. About one-fourth of the patients were exposed to PIMs, and over half were exposed to DDI.

Keywords: Multidose drug dispensing, Inappropriate prescribing, Elderly, Norway, Home care services, Drug-drug interactions

\section{Background}

Multidose drug dispensing (MDD) is an adherence aid that provides patients with machine-dispensed medicines in disposable plastic bags, usually for 14 days. The MDD bags are labeled with the patient's name, the drug names and the time the medicines should be taken. Tablets and capsules can be dispensed via MDD, while medicines such as mixtures, inhalators, topical formulations,

\footnotetext{
* Correspondence: anette.vik.josendal@ehealthresearch.no

${ }^{1}$ Norwegian Centre for E-health Research, University Hospital of North Norway, Tromsø, Norway

${ }^{2}$ Department of Pharmacy, Section for Pharmaceutics and Social Pharmacy, University of Oslo, Oslo, Norway
}

etc., are dispensed in their original packaging. However, all medicines are usually issued on the same prescription as the MDD medicines, including other regular medication, pro re nata (p.r.n) medications, and dietary supplements.

MDD users are typically elderly patients with difficulties handling and administering their medicines, in addition to using several regular medicines [1-3]. This puts them at high risk of experiencing side effects, medication errors, and other adverse drug reactions. Even though the scientific evidence of the effects of MDD is limited $[4,5]$, the system is recommended by the

(c) The Author(s). 2020 Open Access This article is licensed under a Creative Commons Attribution 4.0 International License, which permits use, sharing, adaptation, distribution and reproduction in any medium or format, as long as you give appropriate credit to the original author(s) and the source, provide a link to the Creative Commons licence, and indicate if changes were made. The images or other third party material in this article are included in the article's Creative Commons licence, unless indicated otherwise in a credit line to the material. If material is not included in the article's Creative Commons licence and your intended use is not permitted by statutory regulation or exceeds the permitted use, you will need to obtain permission directly from the copyright holder. To view a copy of this licence, visit http://creativecommons.org/licenses/by/4.0/ The Creative Commons Public Domain Dedication waiver (http://creativecommons.org/publicdomain/zero/1.0/) applies to the data made available in this article, unless otherwise stated in a credit line to the data. 
Norwegian health authorities for use by homecare service patients [6]. The number of patients receiving MDD in Norway has grown from 15,700 patients in 2006 to 90,500 in 2017 [7]. The majority (76\%) receive home care services (HCS), 21\% live in nursing homes and the remaining 5\% are home-dwelling patients who get MDD at their local pharmacy [7]. Most medicines for chronic conditions are reimbursed by the Norwegian National Insurance Scheme. For patients in HCS, the municipality pay the additional costs for the packing of MDD. In 2017, 240,000 patients received HCS; 132,000 were $>67$ years [8]. HCS provide nursing care, such as assistance with personal hygiene, wound care and help to administer medicines, as well as practical help like cleaning, food delivery, and laundry, allowing patients to be able to live at home for as long as possible before moving into a nursing home [9].

Different tools can be used to investigate potentially inappropriate medications (PIMs). The Norwegian General Practice (NORGEP) criteria assess the quality of prescribing to elderly patients in general practice [10]. According to these criteria, about one-third of the elderly Norwegian population is exposed to PIMs [11]. MDD users are, however, more likely to be exposed to PIMs than patients using ordinary dispensing [12-14]. A Norwegian study examined the quality of prescribing to patients receiving MDD in 2009, shortly after the MDD system was established in Norway, and found a prevalence of PIMs of 26\% [2]. However, this study was carried out using an incomplete medication list.

In Norway, over $90 \%$ of prescriptions are electronic [15], however, the MDD prescriptions are still paper-based. The MDD prescriptions have to be faxed to the pharmacy, and GPs find the multidose system more time consuming than electronic prescribing $[16,17]$. As a consequence, there are concerns that the MDD system might lead to the GP making fewer changes in the patients' prescribed medicines, and increase the risk of medication errors in the transition between primary and secondary care, as shown in Sweden $[18,19]$. Patients can also get duplicate prescriptions when GPs prescribe electronic prescriptions in addition to MDD prescriptions [20]. There is, however, an electronic MDD prescribing system in the making, where the prescribing procedure will be the same for MDD prescriptions and ordinary prescriptions. This system is expected to improve the prescribing quality for MDD patients $[15,20]$.

This study aims to assess the prevalence of potentially inappropriate medication use among elderly patients receiving MDD in Norway, before the implementation of an electronic MDD prescribing system.

\section{Methods}

\section{Study design and sample}

We conducted a cross-sectional study using the medication lists from MDD patients in Norway, containing medicines prescribed in June 2018. The MDD supplier delivered about $90 \%$ of all MDDs in Norway at the time of the study, and provided anonymous study data for all patients in their system, containing age, gender and care setting (home dwelling, home care service, or nursing home). From the medication lists, details of drug names, strength, formulation, ATC code [21], dosage schedule and dispensing type (regular drugs dispensed via MDD, regular drugs not dispensed via MDD, or p.r.n medication) were obtained. The original dataset consisted of 87,519 patients and 859,642 medicines. As the NORGEP-criteria are applicable for elderly $\geq 70$ years old, patients under the age of 70 were excluded. Self-pay patients and patients in nursing homes were also excluded because their medication lists are usually incomplete, only containing medicines dispensed as MDD, and no other regular medications and p.r.n. medications.

\section{Outcome measures}

Each patient's drug list was systematically screened for drug-drug interactions (DDIs) using the Norwegian Electronic Prescription Support System where DDIs are classified as either (A) No action necessary, (B) Precautions should be taken, or (C) Should be avoided [22]. Our data were screened for interactions of types B and C.

The PIMs were analysed employing the NORGEP criteria, a validated tool based on the updated American Beers Criteria [23] adapted to the Norwegian formulary, Swedish recommendations [24], and other literature [25]. The NORGEP criteria consists of 21 single substances and 15 drug combinations to be avoided in patients $\geq 70$ years old (Table 1 ). Seven of 36 criteria were handled separately in the analysis: Antibiotics are usually prescribed for short periods, and therefore not listed on MDD prescriptions. Four NORGEP criteria on antibiotics (criterion 23, 24, 30, 35) were thus excluded from our analysis. One criterion (No 36) concerns concomitant prescription of three or more psychotropic medicines. In the analysis for this criterion, psychotropic medications had to be listed as regular use to be included, whereas p.r.n. psychotropic medications were excluded. For the two NORGEP criteria on overuse (no. 12,13), we could only analyse medicines dispensed via MDD and not as other regular medicines or p.r.n., because the dosing schedule was only available for the MDD medication. For the remaining 29 criteria, the criterion would be met if the medication was present in the list, regardless of whether it was listed as regular or p.r.n.

\section{Statistical analysis}

Statistical analysis was performed using Stata/MP 15. Means and standard deviation were used to describe the 
Table 1 Prevalence of potentially inappropriate medications in elderly ( $\geq 70$ years) MDD users in Norway

\begin{tabular}{|c|c|c|c|c|c|c|c|c|c|c|c|c|}
\hline \multirow[b]{2}{*}{ NORGEP single substance criteria } & \multicolumn{2}{|c|}{$\begin{array}{l}\text { Study } \\
\text { population } \\
(n=45,593)\end{array}$} & \multicolumn{2}{|c|}{$\begin{array}{l}\text { Female } \\
(n=30,090)\end{array}$} & \multicolumn{2}{|c|}{$\begin{array}{l}\text { Male } \\
(n=15,503)\end{array}$} & \multicolumn{2}{|c|}{$\begin{array}{l}\text { Age } 70-79 \\
(n=11,435)\end{array}$} & \multicolumn{2}{|c|}{$\begin{array}{l}\text { Age 80-89 } \\
(n=21,633)\end{array}$} & \multicolumn{2}{|c|}{$\begin{array}{l}\text { Age } 90+ \\
(n=12,525)\end{array}$} \\
\hline & $\mathrm{n}$ & $\%$ & $\mathrm{n}$ & $\%$ o & $\mathrm{n}$ & $\%$ & $\mathrm{n}$ & $\%$ & $\mathrm{n}$ & $\%$ o & $\mathrm{n}$ & $\%$ \\
\hline 1. Amitriptyline & 848 & 19 & 639 & 21 & 209 & 13 & 312 & 27 & 381 & 18 & 155 & 12 \\
\hline 2. Doxepin & 61 & 1 & 44 & 1 & 17 & 1 & 17 & 1 & 25 & 1 & 19 & 2 \\
\hline 3. Clomipramine & 74 & 2 & 64 & 2 & 10 & 1 & 31 & 3 & 33 & 2 & 10 & 1 \\
\hline 4. Trimipramine & 162 & 4 & 120 & 4 & 42 & 3 & 60 & 5 & 69 & 3 & 33 & 3 \\
\hline $\begin{array}{l}\text { 5. Chlorpromazine (withdrawn from } \\
\text { Norw. market 2007) }\end{array}$ & 5 & 0 & 5 & 0 & 0 & 0 & 4 & 0 & 1 & 0 & 0 & 0 \\
\hline 6. Chlorprothixene & 387 & 8 & 234 & 8 & 153 & 10 & 222 & 19 & 130 & 6 & 35 & 3 \\
\hline 7. Levomepromazine & 391 & 9 & 255 & 8 & 136 & 9 & 195 & 17 & 140 & 6 & 56 & 4 \\
\hline 8. Prochlorperazine & 288 & 6 & 230 & 8 & 58 & 4 & 59 & 5 & 133 & 6 & 96 & 8 \\
\hline 9. Diazepam & 2911 & 64 & 2175 & 72 & 736 & 47 & 1011 & 88 & 1269 & 59 & 631 & 50 \\
\hline 10. trazepam & 839 & 18 & 595 & 20 & 244 & 16 & 227 & 20 & 342 & 16 & 270 & 22 \\
\hline 11. Flunitrazepam & 15 & 0 & 12 & 0 & 3 & 0 & 7 & 1 & 4 & 0 & 4 & 0 \\
\hline 12. Oxazepam > $30 \mathrm{mg} / 24 \mathrm{~h}$ & 335 & 7 & 253 & 8 & 82 & 5 & 179 & 16 & 116 & 5 & 40 & 3 \\
\hline 13. Zopiclone $>7.5 \mathrm{mg} / 24 \mathrm{~h}$ & 142 & 3 & 98 & 3 & 44 & 3 & 65 & 6 & 52 & 2 & 25 & 2 \\
\hline $\begin{array}{l}\text { 14. Carisoprodol (withdrawn from } \\
\text { Norw. market 2008) }\end{array}$ & 1 & 0 & 0 & 0 & 1 & 0 & 0 & 0 & 1 & 0 & 0 & 0 \\
\hline $\begin{array}{l}\text { 15. Dextropropoxyphene (withdrawn } \\
\text { from Norw. market 2009) }\end{array}$ & 0 & 0 & 0 & 0 & 0 & 0 & 0 & 0 & 0 & 0 & 0 & 0 \\
\hline 16. Theophylline & 107 & 2 & 68 & 2 & 39 & 3 & 45 & 4 & 50 & 2 & 12 & 1 \\
\hline 17. Sotalol & 210 & 5 & 133 & 4 & 77 & 5 & 30 & 3 & 116 & 5 & 64 & 5 \\
\hline 18. Dexchlorpheniramine & 64 & 1 & 42 & 1 & 22 & 1 & 20 & 2 & 26 & 1 & 18 & 1 \\
\hline 19. Promethazine & 85 & 2 & 54 & 2 & 31 & 2 & 31 & 3 & 35 & 2 & 19 & 2 \\
\hline 20. Hydroxyzine & 766 & 17 & 472 & 16 & 294 & 19 & 252 & 22 & 306 & 14 & 208 & 17 \\
\hline 21. Alimemazine/ trimeprazine & 964 & 21 & 634 & 21 & 330 & 21 & 419 & 37 & 395 & 18 & 150 & 12 \\
\hline \multicolumn{13}{|l|}{ NORGEP combination criteria } \\
\hline 22. Warfarin + NSAID & 36 & 1 & 23 & 1 & 13 & 1 & 8 & 1 & 19 & 1 & 9 & 1 \\
\hline 23. Warfarin + ofloxacin/ ciprofloxacin & \multicolumn{12}{|c|}{ NOT ANALYZED: ANTIBIOTICS ARE NOT INCLUDED ON THE MDD PRESCRIPTIONS } \\
\hline 24. Warfarin + erythromycin/ clarithromycin & \multicolumn{12}{|c|}{ NOT ANALYZED: ANTIBIOTICS ARE NOT INCLUDED ON THE MDD PRESCRIPTIONS } \\
\hline 25. Warfarin + SSRI & 348 & 8 & 229 & 8 & 119 & 8 & 83 & 7 & 183 & 8 & 82 & 7 \\
\hline 26. NSAID + ACE inhibitor/ARB & 573 & 13 & 407 & 14 & 166 & 11 & 195 & 17 & 270 & 12 & 108 & 9 \\
\hline 27. NSAID + diuretics & 633 & 14 & 454 & 15 & 179 & 12 & 181 & 16 & 272 & 13 & 180 & 14 \\
\hline 28. NSAID + glucocorticoids & 206 & 5 & 160 & 5 & 46 & 3 & 68 & 6 & 98 & 5 & 40 & 3 \\
\hline 29. NSAID + SSRI & 370 & 8 & 309 & 10 & 61 & 4 & 139 & 12 & 174 & 8 & 57 & 5 \\
\hline 30. Erythromycin/ clarithromycin + statin & \multicolumn{12}{|c|}{ NOT ANALYZED: ANTIBIOTICS ARE NOT INCLUDED ON THE MDD PRESCRIPTIONS } \\
\hline $\begin{array}{l}\text { 31. ACE inhibitor+ potassium /potassium- } \\
\text { sparing diuretic }\end{array}$ & 1035 & 23 & 625 & 21 & 410 & 26 & 324 & 28 & 457 & 21 & 254 & 20 \\
\hline 32. Fluoxetine/ fluvoxamine + TCA & 3 & 0 & 2 & 0 & 1 & 0 & 2 & 0 & 1 & 0 & 0 & 0 \\
\hline $\begin{array}{l}\text { 33. Beta blocker + cardioselective } \\
\text { calcium antagonist }\end{array}$ & 147 & 3 & 107 & 4 & 40 & 3 & 28 & 2 & 67 & 3 & 52 & 4 \\
\hline 34. Diltiazem + lovastatin/ simvastatin & 34 & 1 & 22 & 1 & 12 & 1 & 13 & 1 & 15 & 1 & 6 & 0 \\
\hline 35. Erythromycin/clarithromycin + carbamazepine & \multicolumn{12}{|c|}{ NOT ANALYZED: ANTIBIOTICS ARE NOT INCLUDED ON THE MDD PRESCRIPTIONS } \\
\hline $\begin{array}{l}\text { 36. Concomitant prescription of three or more } \\
\text { drugs from the groups centrally acting analgesics, } \\
\text { antipsychotics, antidepressants, and/or benzodiazepines }\end{array}$ & 4906 & 108 & 3775 & 125 & 1131 & 73 & 1959 & 171 & 2047 & 95 & 900 & 72 \\
\hline
\end{tabular}


sample characteristics, and student's t-test was applied to compare means. Binary logistic regression was used to assess the relationships between inappropriate mediations (yes/no) for each patient, drug-drug-interactions (yes/no), and gender, age, and number of medicines. For the analysis, age was categorized into 10 -year age intervals.

\section{Ethics}

The study was approved by the Data Protection Officer at the University Hospital of North Norway. All data were anonymous and deemed not to need approval by the Regional Committees for Medical and Health Research Ethics.

\section{Results}

As shown in Fig. 1, after exclusions the final analysis included 45,593 patients, i.e. approximately one-third of the patients $\geq 70$ years old receiving home care services in Norway [8]. The study population characteristics are shown in Table 2. The mean number of regular medications was $8.2($ median $=8)$, of which $6.1 \quad($ median $=6)$ were dispensed as MDD. The mean number of total prescribed medicines was 10.6 (median $=10$ ). In total $85 \%$ used 5 or more medicines regularly and $33 \%$ used 10 or more medicines. In addition, $20 \%$ of the patients used dietary supplements. The mean age was $84.7(\mathrm{SD}=7.3)$. Women were on average older than men (85.5 vs. 83.1, $p<0.001$ ), and used a higher number of drugs (11.1 vs 10.7, $\mathrm{p}<0.001)$. Drugs for the cardiovascular and nervous-system were the most frequently used drug groups. The most commonly prescribed therapeutic subgroups were antithrombotics (70\% of patients), non-opioid analgesics (58\%), beta-blockers (47\%), lipid-modifying drugs (41\%) and hypnotics/sedatives (39\%) (Table 3).

\section{Potentially inappropriate medications}

According to the NORGEP-criteria, 12,319 patients (27\%) received one or more PIMs (Fig. 2). Table 1 shows

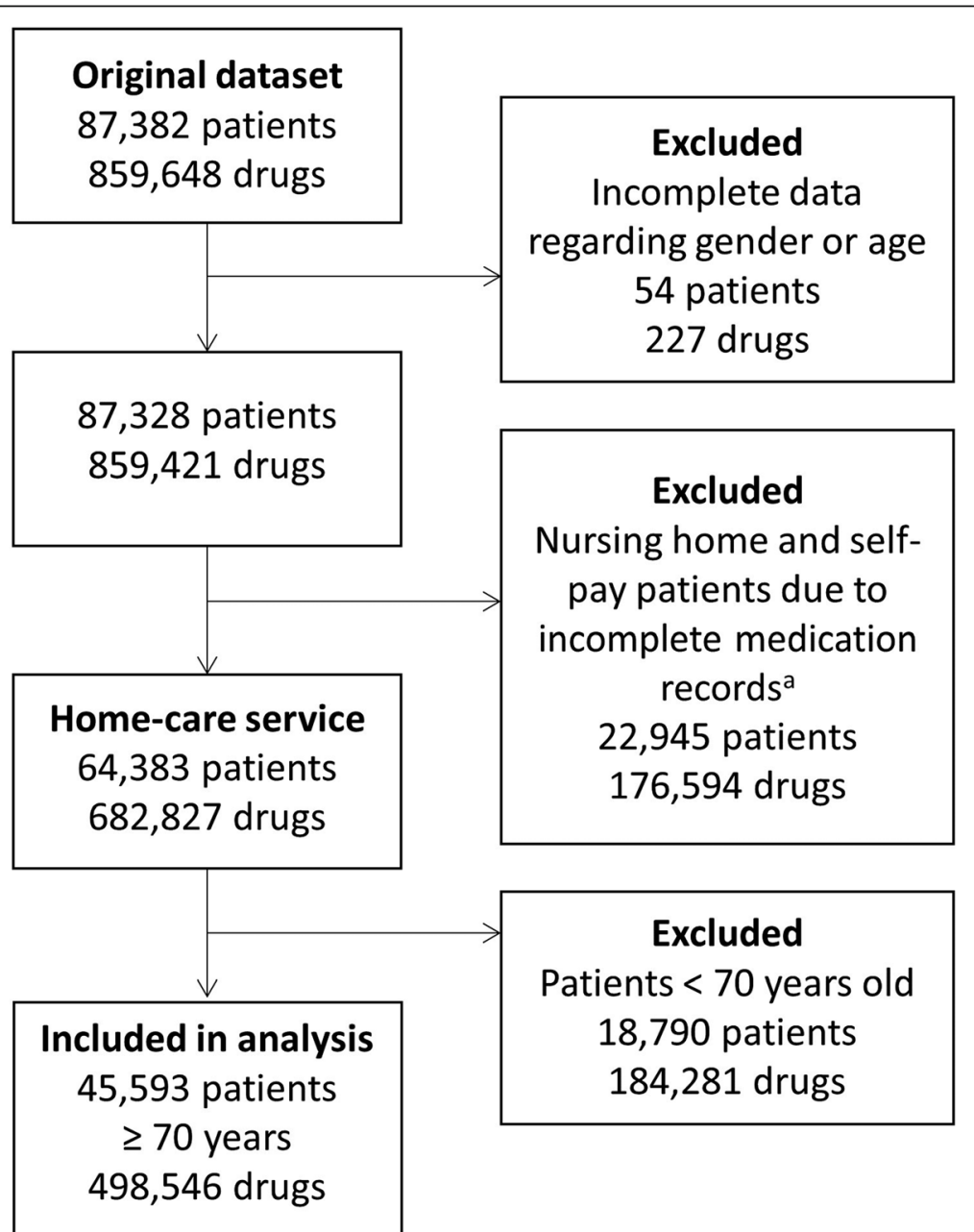

Fig. 1 Patients using multidose drug dispensing in Norway in 2018: Exclusion flow chart of cases. a: Lists from the nursing home and self-pay patients only contain medicines dispensed as MDD, and not other regular medicines and p.r.n medication 
Table 2 Study population characteristics and drug use $(N=45,593)$

\begin{tabular}{|c|c|c|c|c|c|c|c|c|c|c|}
\hline & \multicolumn{2}{|c|}{ Study population } & \multicolumn{2}{|c|}{$\begin{array}{l}\text { Regular drugs } \\
\text { Dispensed as MDD }\end{array}$} & \multicolumn{2}{|c|}{$\begin{array}{l}\text { Regular drugs } \\
\text { Not dispensed as MDD }\end{array}$} & \multicolumn{2}{|c|}{ P.r.n drugs } & \multicolumn{2}{|c|}{ Total number of drugs } \\
\hline & $\bar{n}$ & (\%) & mean & (SD) & mean & (SD) & mean & $\overline{(S D)}$ & mean & (SD) \\
\hline Total & 45,593 & $(100)$ & 6.3 & $(2.8)$ & 2.2 & (2.0) & 2.4 & (2.3) & 10.9 & (5.0) \\
\hline \multicolumn{11}{|l|}{ Age } \\
\hline 70-79 & 11,435 & (25) & 6.9 & (3.1) & 2.3 & $(2.1)$ & 2.4 & $(2.4)$ & 11.6 & $(5.5)$ \\
\hline $80-89$ & 21,633 & (47) & 6.4 & (2.8) & 2.2 & (1.9) & 2.4 & (2.3) & 11.0 & $(4.9)$ \\
\hline $90+$ & 12,525 & (27) & 5.7 & (2.6) & 2.1 & (1.9) & 2.4 & $(2.2)$ & 10.3 & (4.6) \\
\hline \multicolumn{11}{|l|}{ Gender } \\
\hline Female & 30,090 & (66) & 6.4 & (2.9) & 2.5 & $(2.3)$ & 2.6 & (1.9) & 11.1 & (5.1) \\
\hline Male & 15,503 & (34) & 6.2 & (2.8) & 2.2 & $(2.2)$ & 2.2 & (2.0) & 10.7 & (4.9) \\
\hline
\end{tabular}

Table 3 The 25 most frequently used drug groups among MDD patients with home care services $(N=45,593)$

\begin{tabular}{|c|c|c|c|c|c|c|c|c|c|c|c|}
\hline \multirow[t]{2}{*}{$\begin{array}{l}\text { ATC } \\
\text { level } 3\end{array}$} & \multirow[t]{2}{*}{ Therapeutic drug group } & \multicolumn{2}{|c|}{$\begin{array}{l}\text { Regular drugs } \\
\text { Dispensed as } \\
\text { MDD }\end{array}$} & \multicolumn{2}{|c|}{$\begin{array}{l}\text { Regular drugs } \\
\text { Not dispensed } \\
\text { as MDD }\end{array}$} & \multicolumn{2}{|c|}{$\begin{array}{l}\text { P.r.n } \\
\text { medications }\end{array}$} & \multicolumn{2}{|c|}{$\begin{array}{l}\begin{array}{l}\text { Drug use } \\
\text { female } \\
(n=30,090)\end{array} \\
\end{array}$} & \multicolumn{2}{|c|}{$\begin{array}{l}\text { Drug use } \\
\text { male } \\
(n=15,503)\end{array}$} \\
\hline & & $\mathrm{n}$ & $(\%)$ & $\mathrm{n}$ & $(\%)$ & $\mathrm{n}$ & $(\%)$ & $\mathrm{n}$ & $(\%)$ & $n$ & $(\%)$ \\
\hline $\mathrm{B} 01 \mathrm{~A}$ & Antithrombotic agents & 27,477 & $(60)$ & 5744 & (13) & 65 & (0) & 19,845 & $(66)$ & 12,004 & $(77)$ \\
\hline N02B & Other analgesics and antipyretics & 11,393 & $(25)$ & 1448 & (3) & 16,024 & (35) & 18,829 & $(63)$ & 7846 & $(51)$ \\
\hline C07A & Beta blocking agents & 21,522 & $(47)$ & 79 & $(0)$ & 174 & (0) & 13,796 & $(46)$ & 7709 & $(50)$ \\
\hline C10A & Lipid modifying agents, plain & 18,545 & $(41)$ & 133 & $(0)$ & 10 & (0) & 10,911 & $(36)$ & 7643 & (49) \\
\hline N05C & Hypnotics and sedatives & 10,485 & (23) & 495 & $(1)$ & 7426 & (16) & 12,841 & $(43)$ & 5984 & (39) \\
\hline $\mathrm{A} 02 \mathrm{~B}$ & $\begin{array}{l}\text { Drugs for peptic ulcer and gastro-oesophageal } \\
\text { reflux disease }\end{array}$ & 16,036 & (35) & 289 & (1) & 1599 & (4) & 11,371 & (38) & 5266 & (34) \\
\hline $\mathrm{CO3C}$ & High-ceiling diuretics & 13,832 & (30) & 136 & $(0)$ & 1992 & (4) & 9962 & (33) & 4939 & $(32)$ \\
\hline $\mathrm{A} 06 \mathrm{~A}$ & Drugs for constipation & 578 & $(1)$ & 8926 & $(20)$ & 7918 & $(17)$ & 9502 & $(32)$ & 4727 & (30) \\
\hline N02A & Opioids & 3771 & (8) & 3758 & (8) & 9375 & $(21)$ & 9869 & (33) & 3695 & (24) \\
\hline N06A & Antidepressants & 11,564 & $(25)$ & 429 & $(1)$ & 178 & (0) & 8807 & $(29)$ & 3377 & $(22)$ \\
\hline N05B & Anxiolytics & 3999 & (9) & 219 & (0) & 7743 & $(17)$ & 8205 & $(27)$ & 3171 & (20) \\
\hline $\mathrm{A} 12 \mathrm{~A}$ & Calcium & 10,328 & (23) & 336 & (1) & 19 & $(0)$ & 8821 & $(29)$ & 3155 & (20) \\
\hline $\mathrm{COBC}$ & $\begin{array}{l}\text { Selective calcium channel blockers with mainly } \\
\text { vascular effects }\end{array}$ & 9055 & $(20)$ & 79 & $(0)$ & 81 & $(0)$ & 6269 & $(21)$ & 3060 & $(20)$ \\
\hline R03A & Adrenergics, inhalants & 1 & $(0)$ & 6809 & $(15)$ & 4651 & $(10)$ & 5542 & $(18)$ & 2901 & $(19)$ \\
\hline A11E & Vitamin B-complex, including combinations & 8262 & $(18)$ & 173 & $(0)$ & 36 & $(0)$ & 5072 & $(17)$ & 2721 & $(18)$ \\
\hline B03B & Vitamin B12 and folic acid & 2968 & $(7)$ & 5792 & $(13)$ & 192 & $(0)$ & 5573 & $(19)$ & 2698 & $(17)$ \\
\hline CO9A & ACE inhibitors, plain & 7569 & $(17)$ & 37 & $(0)$ & 1 & (0) & 4539 & $(15)$ & 2644 & $(17)$ \\
\hline C01D & Vasodilators used in cardiac diseases & 3359 & (7) & 372 & (1) & 5997 & $(13)$ & 4851 & $(16)$ & 2498 & (16) \\
\hline $\mathrm{H} 03 \mathrm{~A}$ & Thyroid preparations & 7050 & $(15)$ & 29 & $(0)$ & 2 & $(0)$ & 5839 & (19) & 1981 & $(13)$ \\
\hline CO9C & Angiotensin II receptor blockers (ARBs), plain & 6466 & $(14)$ & 41 & $(0)$ & 2 & (0) & 4547 & $(15)$ & 1958 & $(13)$ \\
\hline $\mathrm{A} 10 \mathrm{~B}$ & Blood glucose lowering drugs, excluding insulins & 5734 & $(13)$ & 229 & $(1)$ & 12 & $(0)$ & 3328 & $(11)$ & 1927 & $(12)$ \\
\hline R06A & Antihistamines for systemic use & 3630 & (8) & 133 & $(0)$ & 1984 & $(4)$ & 3975 & $(13)$ & 1872 & $(12)$ \\
\hline D07A & Corticosteroids, plain & 1 & $(0)$ & 989 & $(2)$ & 4504 & $(10)$ & 3354 & $(11)$ & 1844 & $(12)$ \\
\hline A11C & $\begin{array}{l}\text { Vitamin } A \text { and } D \text {, including combinations of } \\
\text { the two }\end{array}$ & 4709 & $(10)$ & 209 & $(0)$ & 61 & $(0)$ & 3144 & $(10)$ & 1819 & (12) \\
\hline R05C & $\begin{array}{l}\text { Expectorants, excl. Combinations with cough } \\
\text { suppressants }\end{array}$ & 15 & (0) & 1187 & (3) & 3820 & (8) & 3003 & (10) & 1622 & (10) \\
\hline
\end{tabular}




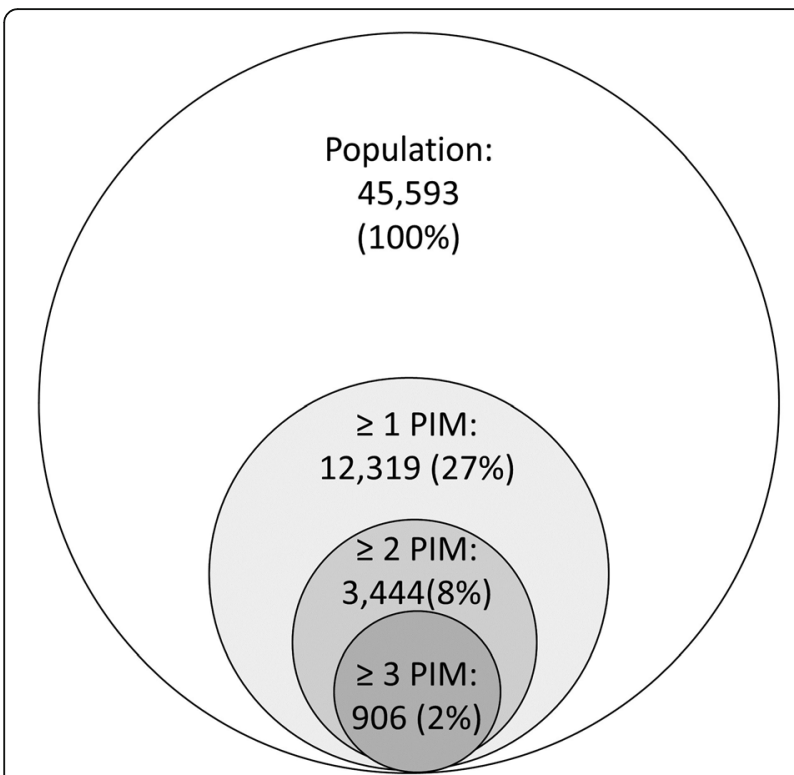

Fig. 2 Prevalence of potentially inappropriate medications (PIMs) per patient

the prevalence of the different PIMs. Concomitant use of three or more psychotropic and/or opioid drugs was the most prevalent PIM (10.8\%), followed by prescribing of diazepam (6.4\%). Criterion 1-8 and 18-21 concerns anticholinergic drugs; 3843 patients $(8.4 \%)$ had one or more of those criteria. The number of PIMs was significantly correlated with the number of drugs prescribed $(p<0.001)$. After adjustment for age, women had a higher risk of PIMs $(\mathrm{OR}=1.50,95 \% \mathrm{CI}: 1.43-1.58)$. The risk of PIMs decreased with patient age (Table 4).

\section{Drug-drug interactions}

The screening for DDI revealed 59,414 interactions in $27,012(59 \%)$ of the patients. Of the total number of interactions, $97.7 \%$ were classified as "type B - precautions should be taken", and $2.3 \%$ as "type C- should be avoided". Figure 3 illustrates the number of patients

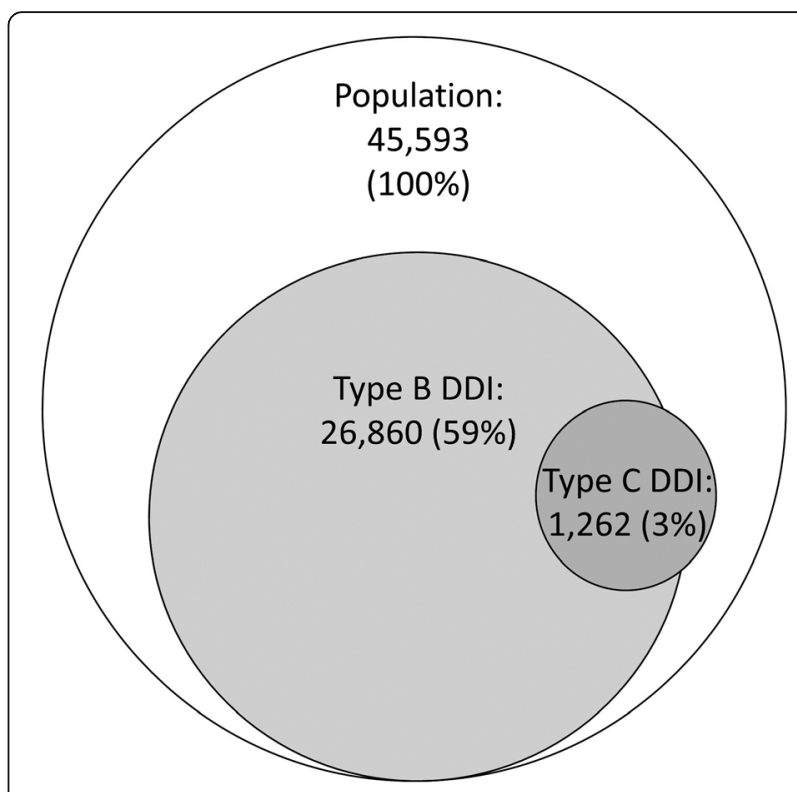

Fig. 3 Prevalence of drug-drug interactions (DDls) per patient. Type $\mathrm{B}=$ " Precautions should be taken", Type $C=$ " should be avoided"

with type B and C DDIs. DDIs increased with the number of prescribed drugs and decreased with patient age (Table 4). Women had a higher risk of DDIs than men $(\mathrm{OR}=1.43$, 95\% CI: $1.37-1.50)$.

\section{Discussion}

The medication use in elderly patients using MDD in home care services in Norway is high, with about onethird of the patients using 10 or more drugs regularly. Approximately one-fourth received potentially inappropriate medications, and over half was exposed to drug-drug interactions. Females had a higher risk than men to experience both PIMs and DDIs, and both PIMs and DDIs were positively correlated with the number of medicines prescribed and negatively associated with patient age.

Table 4 Factors associated with PIMs and DDIs in elderly (> 70 years) multidose users in Norway in 2018

\begin{tabular}{|c|c|c|c|c|c|c|c|c|c|c|c|c|c|}
\hline \multicolumn{2}{|c|}{ Study population } & \multicolumn{4}{|c|}{$\begin{array}{l}\text { Potentially inappropriate } \\
\text { medications (PIM) }\end{array}$} & \multicolumn{8}{|c|}{$\begin{array}{l}\text { Drug-drug interactions } \\
\text { (DDI) }\end{array}$} \\
\hline & \multirow[b]{2}{*}{$\mathrm{n}$} & \multirow[b]{2}{*}{$\mathbf{n}$} & \multirow[b]{2}{*}{ (\%) } & \multirow[b]{2}{*}{ OR } & \multirow[b]{2}{*}{$(95 \% \mathrm{Cl})$} & \multirow[b]{2}{*}{$\mathrm{n}$} & \multirow[b]{2}{*}{ (\%) } & \multirow[b]{2}{*}{ OR } & \multirow[b]{2}{*}{$(95 \% \mathrm{Cl})$} & \multicolumn{2}{|c|}{ Type $B^{a}$} & \multicolumn{2}{|c|}{ Type $C^{a}$} \\
\hline & & & & & & & & & & $\mathrm{n}$ & (\%) & $\mathrm{n}$ & (\%) \\
\hline Age 70-79 & 11,435 & 4072 & (35.6) & 1 & (ref) & 7227 & $(63.2)$ & 1 & (ref) & 7171 & $(62.7)$ & 493 & (4.3) \\
\hline Age 80-89 & 21,633 & 5449 & $(25.2)$ & 0.61 & $(0.57-0.64)$ & 13,000 & $(60.1)$ & 0.90 & $(0.85-0.95)$ & 12,935 & (59.8) & 543 & (2.5) \\
\hline Age 90+ & 12,525 & 2793 & $(22.3)$ & 0.55 & $(0.52-0.59)$ & 6785 & $(54.2)$ & 0.76 & $(0.72-0.81)$ & 6754 & (53.9) & 226 & (1.8) \\
\hline No. of drugs & 45,593 & NA & & $1.15^{\mathrm{b}}$ & $(1.15-1-16)$ & NA & & $1.30^{\mathrm{b}}$ & $(1.28-1.30)$ & NA & & NA & \\
\hline Male & 15,503 & 8814 & $(22.6)$ & 1 & (ref) & 8354 & $(53.9)$ & 1 & (ref) & 8294 & (53.5) & 420 & $(2.7)$ \\
\hline Female & 30,090 & 3505 & $(29.3)$ & 1.50 & $(1.43-1.58)$ & 18,658 & $(62.0)$ & 1.43 & $(1.37-1.50)$ & 18,566 & $(61.7)$ & 842 & (2.8) \\
\hline
\end{tabular}

a: Type B = "Precautions should be taken", Type $\mathrm{C}=$ "should be avoided"

${ }^{b}$ : Increase in odds for PIMs and DDIs for every one unit increase in the number of drugs 


\section{Drug utilization}

The most commonly prescribed medication groups are the same in the MDD population as in the general elderly population not receiving MDD, however, the overall prevalence is higher in MDD patients (Table 3) [26]. Antithrombotic agents $(70 \%$ in the present study vs. $47 \%$ general elderly population) and analgesics ( $58 \%$ vs. $25 \%$ ) are more frequently prescribed in MDD patients than the general elderly population. Women were more frequently prescribed medications acting on the nervous system and less cardiovascular drugs compared to men. The MDD patients used on average 8.2 drugs regularly, of which 6.1 were dispensed as MDD. In addition, 2.4 drugs were listed as p.r.n. medications. This is a higher number of medicines compared to the Norwegian elderly community-dwelling patients [26, 27], and thus supports previous findings that MDD patients tend to use more medicines than patients with ordinary dispensing $[1,3,13]$. However, since our study population receives HCS, they also have greater care needs than the general population.

Polypharmacy has been associated with negative health outcomes such as falls, adverse drug reactions, hospitalization, and mortality $[28,29]$. However, lack of proper adjustment for confounders has been mentioned as a challenge in these studies [28-30]. The recent ESTHER study found no independent association between polypharmacy and non-cancer mortality when adjusting for confounding by indication [31, 32]. The high prevalence of polypharmacy in our study might thus be a reflection of a high morbidity in the study population. One previous study has shown that introducing an MDD system increases the number of medicines prescribed [13], though another observed the same increase in the control group where MDD was not introduced [33].

\section{Potentially inappropriate medications}

In our study, $27 \%$ of the patients had at least one PIM. A systematic review of PIMs found an estimated prevalence of $22.6 \%$ in European community-dwelling older adults [34]. The prevalence, however, varied greatly between the studies due to different quality indicators used and differences in the study populations included. Nyborg et al. used the NORGEP criteria and found a $34.8 \%$ prevalence of PIMs for the entire Norwegian home-dwelling elderly population [27]. This is higher than in our study, despite our study population using more medicines. An explanation is that we have excluded the criteria on the use of antibiotics. In addition, we used different data sources; Nyborg et al. used dispensed medicines while we used prescribed medicines (see strength and limitation).
Our prevalence of PIMs according to the NORGEP criteria (27\%) is comparable with Halvorsen et al. (24.6\%) a decade ago [2]. Though our prevalence (27\%) is somewhat higher, this is expected since we have looked at the entire medication list of the patients, and not just the medicines dispensed as MDD. The prescribing quality for MDD patients over the past decade does not seem to have improved, despite increased focus on medication reviews and deprescribing [35, 36].

Concomitant use of three or more psychotropic drugs is a PIM in the NORGEP list, as this increases the risk of muscular weakness, falls, fractures and cognitive impairment [25]. Similar to our study, Halvorsen et al. found that this was the most prevalent PIM in MDD patients, with $9.0 \%$ meeting this criterion compared to $10.8 \%$ in our study. This is high compared to the general Norwegian elderly population, where the prevalence is $4.8 \%$ [27], however, it is lower in the Swedish studies of MDD patients, which found a prevalence of between 16.0 and $22.1 \%[3,13,14]$.

\section{Drug-drug interactions}

The prevalence of DDIs in older patients vary greatly in the literature, from a few percent to almost $60 \%$ [2, 37, 38]. A prevalence of $59 \%$ as found in our study, is thus high. The majority of DDIs are "Type B - precautions should be taken" (Table 4). The suggested precautions for these DDIs include changing the ingestion time, increased monitoring of symptoms or side-effects and dose adjustments. The data in our study do not include information on whether precautions have actually been taken, however, the DDIs might not be clinically relevant if they have.

The prevalence of the most serious DDIs (type C) is more similar in our study and the literature. In our study, $2.7 \%$ of the patients had such interactions, while the prevalence is between 0.4 and $9.0 \%$ in previous studies of MDD patients [2, 3, 38, 39]. As the MDD prescriptions are systematically screened for DDIs using the same database we have used in this study, the GP is likely aware of these interactions at the time of the prescribing. Considering the low prevalence of the most serious DDIs we could thus question the clinical relevance of the interactions found in this study, as the doctor might already have judged the co-prescribing as necessary with no better alternatives available, and started appropriate monitoring of the patients.

\section{Predictors of PIMs and DDIs}

We found that younger elderly (70-79years) had a higher number of inappropriate drugs, a relationship confirmed by others $[2,39,40]$. However, Nyborg found that the age effect was not present in the multivariate analysis when in addition to age and gender, the number of prescribers was also included [27]. Information about 
the number of prescribers was, however not available for our study. Women having a higher risk of experiencing DDIs and PIMs, is also consistent with previous findings $[2,27,38,40,41]$. This is partly explained by the fact that women are more commonly prescribed sedatives, analgetics and anxiolytics (See Table 3) [41], and many of the PIMs are related to these drugs.

\section{Strengths and limitations}

A major strength of this study is that it represents almost $90 \%$ of the MDD users in Norway. In addition, the medication lists include dietary supplements. This data gives comprehensive information on drug use for these patients. HCS patients and MDD-prescriptions cannot be specifically identified in the Norwegian Prescription Database [42]. In that sense, our data on medicines use is unique. There could still, however, be errors or omissions in the data. The patient can get prescriptions on antibiotics and other short-term treatments or buy overthe-counter medicines, which are not listed on the MDD prescription. Most Nordic countries have databases over dispensed prescriptions [43] while the medication list used in our study represents prescribed medications. Our data thus includes prescriptions issued by a physician but not filled ("primary non-compliance"), which makes comparison to other Nordic studies difficult.

As with all register-based studies, one cannot conclude if PIMs have led to actual drug-related problems for the patients. A recent study looking at patients with multimorbidity acutely admitted to the hospital, found that strict adherence to the NORGEP-criteria could have prevented $15 \%$ of the serious adverse drug reactions [44]. The NORGEP-criteria was published in 2009. Changes in both prescribing patterns and the Norwegian formulary have led to some of the items on the NORGEP list to be outdated (e.g. Table 1 shows that three drugs have been withdrawn from the Norwegian marked), and newer therapies which can be considered inappropriate for elderly have not been included. In addition, drugspecific criteria like the NORGEP-criteria do not capture all aspects of prescribing quality, as it, for example, does not address problems like under-prescribing like e.g. the START/STOPP criteria [35].

\section{Unfulfilled potential of the MDD system}

Having all the patients' medicines on the same prescription puts the pharmacist in a unique position to assess the prescribing and identify PIMs and DDIs. Having a complete overview over the patient's medication use have been suggested as an explanation for why MDD patients seem to have fewer serious DDIs than patients with ordinary prescribing [14]. The systematic screening for DDIs for MDD patients might also explain the relatively low prevalence $(2.7 \%)$ of serious DDIs in the present study. However, there still seems to be an unfulfilled potential of using the MDD system to systematically identify PIMs. The screening could be used to identify high-risk patients who could be targeted for interprofessional medication reviews which again could raise awareness of inappropriate prescribing. When the electronic prescribing system is implemented, this also opens possibilities for the pharmacist to give direct feedback to the prescriber when problems are detected.

Further research is needed to explore whether high overall medication use is a result of the MDD system in itself, or whether it is due to differences in patient characteristics for patients with ordinary prescriptions compared to MDD.

\section{Conclusions}

This study suggests that potentially inappropriate prescribing is common in elderly patients receiving MDD in Norway, as about one-fourth of the patients were exposed to PIMs, and over half were exposed to DDIs. However, previous studies suggest that both PIMs and DDIs are common also in patients not receiving MDD. Comparing our results to previous Norwegian studies, we do not find the same difference in prescribing quality between patients with MDD and patients with ordinary prescribing, as is shown in Sweden. However, we see that the overall drug consumption in MDD patients is higher than the general population, with about one third being prescribed 10 or more drugs regularly. In addition, there is more frequent co-prescribing of psychotropic and opioid drugs in MDD patients.

\section{Abbreviations \\ MDD: Multidose drug dispensing; PIM: Potentially inappropriate medication; DDI: Drug-drug interactions; HCS: Home care service; NORGEP-criteria: The} Norwegian General Practice-criteria

\section{Acknowledgments}

We thank Apotek 1 Gruppen AS for providing data for this study.

\section{Authors' contributions}

AVJ, AGG, TSB conceived the study design. Material preparation, data collection and the initial analysis were performed by AVJ. The first draft of the manuscript was written by AVJ. AVJ, TSB and AGG revised the manuscript. All authors and approved the final version of the manuscript.

\section{Funding}

This study was internally funded by the Norwegian Centre for E-health Research.

\section{Availability of data and materials}

The data that support the findings of this study are provided by Apotek 1 Gruppen AS and are not publicly available. Data are however available from the corresponding authors upon reasonable request and with permission of Apotek 1 Gruppen AS.

\section{Ethics approval and consent to participate}

The aim of the project falls outside the Health Research Act and the study was deemed not to need approval by the Regional Committees for Medical and Health Research Ethics. The study was approved by the Data Protection Officer at the University Hospital of North Norway and the Data Protection 
Officer at Apotek 1 Gruppen AS. Because it was a retrospective study and all data was anonymised by Apotek 1, the need to obtain written informed consent was waived.

\section{Consent for publication}

Not applicable.

\section{Competing interests}

Apotek 1 Gruppen AS, a supplier of multidose dispensed drugs in Norway, provided data for this study. A.V. Jøsendal is employed by Apotek 1 Gruppen AS. The other authors declare no conflict of interest relevant to this study.

\section{Received: 10 October 2019 Accepted: 22 July 2020}

\section{Published online: 05 August 2020}

\section{References}

1. Mertens BJ, Kwint HF, van Marum RJ, Bouvy ML. Are multidose drug dispensing systems initiated for the appropriate patients? Eur J Clin Pharmacol. 2018;74(9):1159-64. https://doi.org/10.1007/s00228-018-2478-5.

2. Halvorsen $\mathrm{KH}$, Granas $\mathrm{AG}$, Engeland $\mathrm{A}$, Ruths $\mathrm{S}$. Prescribing quality for older people in Norwegian nursing homes and home nursing services using multidose dispensed drugs. Pharmacoepidemiol Drug Saf. 2012;21(9):929-36.

3. Sjoberg C, Edward C, Fastbom J, Johnell K, Landahl S, Narbro K, Wallerstedt SM. Association between multi-dose drug dispensing and quality of drug treatment--a register-based study. PLoS One. 2011;6(10):e26574. https://doi. org/10.1371/journal.pone.0026574.

4. Sinnemaki J, Sihvo S, Isojarvi J, Blom M, Airaksinen M, Mantyla A. Automated dose dispensing service for primary healthcare patients: a systematic review. Syst Rev. 2013;2:1. https://doi.org/10.1186/2046-4053-2-1.

5. Halvorsen KH, Granas AG. Multi-dose dispensed drugs in Scandinavia - a systematic review of possibilities and limitations. Norsk Farmaceutisk Tidsskrift. 2012;120(4):22-7

6. Ministry of Health and Care Services (2015) [White Paper on Medicinal Products - Correct use - better health].

7. The Norwegian Pharmacy Association (2018) Pharmacies and Pharmaceuticals in Norway 2017. www.apotekstatistikk.no.

8. Statistics Norway (2019) 06969: users of nursing and care services, by age, kind of service, contents and year. Dataset. https://www.ssb.no/en/.

9. Holm SG, Mathisen TA, Sæterstrand TM, Brinchmann BS. Allocation of home care services by municipalities in Norway: a document analysis. BMC Health Serv Res. 2017;17(1):673. https://doi.org/10.1186/s12913-017-2623-3.

10. Rognstad S, Brekke M, Fetveit A, Spigset O, Wyller TB, Straand J. The Norwegian general practice (NORGEP) criteria for assessing potentially inappropriate prescriptions to elderly patients. A modified Delphi study. Scand J Prim Health Care. 2009;27(3):153-9. https://doi.org/10.1080/ 02813430902992215

11. Nyborg G, Straand J, Brekke M. Inappropriate prescribing for the elderly--a modern epidemic? Eur J Clin Pharmacol. 2012;68(7):1085-94. https://doi.org/ 10.1007/s00228-012-1223-8

12. Olsson J, Bergman A, Carlsten A, Oke T, Bernsten C, Schmidt IK, Fastbom J. Quality of drug prescribing in elderly people in nursing homes and specia care units for dementia: a cross-sectional computerized pharmacy register analysis. Clin Drug Investig. 2010;30(5):289-300. https://doi.org/10.2165/ 11534320-000000000-00000.

13. Wallerstedt SM, Fastbom J, Johnell K, Sjoberg C, Landahl S, Sundstrom A Drug treatment in older people before and after the transition to a multidose drug dispensing system--a longitudinal analysis. PLoS One. 2013;8(6): e67088. https://doi.org/10.1371/journal.pone.0067088.

14. Johnell K, Fastbom J. Multi-dose drug dispensing and inappropriate drug use: a nationwide register-based study of over 700,000 elderly. Scand J Prim Health Care. 2008;26(2):86-91. https://doi.org/10.1080/02813430802022196.

15. The Norwegian Directorate of eHealth (2019) [National e-health monitor]. https://ehelse.no/strategi/nasjonal-e-helsemonitor. Accessed 02 Apr 2019.

16. Wekre LJ, Melby L, Grimsmo A. Early experiences with the multidose drug dispensing system--a matter of trust? Scand J Prim Health Care. 2011;29(1): 45-50. https://doi.org/10.3109/02813432.2011.554002.

17. Heier K, Olsen V, Rognstad S, Straand J, Toverud E. Healthcare providers' experience with multi-dose packaged medicines. Tidsskr Nor Laegeforen. 2007;127(18):2382-5.
18. Sjoberg C, Ohlsson H, Wallerstedt SM. Association between multi-dose drug dispensing and drug treatment changes. Eur J Clin Pharmacol. 2012;68(7): 1095-101. https://doi.org/10.1007/s00228-012-1230-9.

19. Reuther LO, Lysen C, Faxholm M, Salomon L, Hendriksen C. Multi-dose drug dispensing is a challenge across the primary-secondary care interface. Dan Med Bull. 2011;58(12):A4341.

20. The Norwegian Directorate of Health (2015) [Multidose - status and the way forward]. IS-2422. Oslo.

21. WHO. Collaborating Centre for Drug Statistics Methodology (2018) ATC/ DDD index. https://www.whocc.no/atc_ddd_index/.

22. The Norwegian Medicines Agency (Updated 2016) FEST implementation guidelines v2.1.

23. Fick DM, Cooper JW, Wade WE, Waller JL, Maclean JR, Beers MH. Updating the Beers criteria for potentially inappropriate medication use in older adults: results of a US consensus panel of experts. Arch Intern Med. 2003: 163(22):2716-24. https://doi.org/10.1001/archinte.163.22.2716.

24. Swedish National Board of Health and Welfare. Indicators for assessing the quality of the medication of elderly patients, vol. 73; 2003. Stockholm.

25. Rognstad S, Brekke M, Fetveit A, Spigset O, Wyller TB, Straand J. The Norwegian general practice (NORGEP) criteria for assessing potentially inappropriate prescriptions to elderly patients: a modified Delphi study. Scand J Prim Health Care. 2009;27(3):153-9.

26. Berg C, Blix HS, Fenne O, Furu K, Hjellvik V, Husabø KJ, Litleskare I, Rønning M, Sakshaug S, Selmer R, Søgaard A-J, Torheim S. The Norwegian Prescription Database 2013-2017. Topic: drug use in the elderly, vol. 2. Oslo: The Norwegian Institute of Public Health; 2018.

27. Nyborg G, Straand J, Brekke M. Inappropriate prescribing for the elderly-a modern epidemic? Eur J Clin Pharmacol. 2012;68(7):1085-94.

28. Fried TR, O'Leary J, Towle V, Goldstein MK, Trentalange M, Martin DK. Health outcomes associated with Polypharmacy in community-dwelling older adults: a systematic review. J Am Geriatr Soc. 2014;62(12):2261-72. https://doi.org/10.1111/jgs.13153.

29. Leelakanok N, Holcombe AL, Lund BC, Gu X, Schweizer ML. Association between polypharmacy and death: a systematic review and meta-analysis. J Am Pharm Assoc. 2017;57(6):729-738.e710. https://doi.org/10.1016/j.japh. 2017.06.002

30. Wastesson JW, Morin L, Tan ECK, Johnell K. An update on the clinical consequences of polypharmacy in older adults: a narrative review. Expert Opin Drug Saf. 2018;17(12):1185-96. https://doi.org/10.1080/14740338.2018.1546841.

31. Schottker B, Saum KU, Muhlack DC, Hoppe LK, Holleczek B, Brenner H. Polypharmacy and mortality: new insights from a large cohort of older adults by detection of effect modification by multi-morbidity and comprehensive correction of confounding by indication. Eur J Clin Pharmacol. 2017;73(8):1041-8. https://doi.org/10.1007/s00228-017-2266-7.

32. Schottker B, Muhlack DC, Hoppe LK, Holleczek B, Brenner H. Updated analysis on polypharmacy and mortality from the ESTHER study. Eur J Clin Pharmacol. 2018:74(7):981-2. https://doi.org/10.1007/s00228-018-2445-1.

33. Hindahammer A, Ali Z, Pedersen SH, Steinland E, Saether EM, Sorbraten T. Does multidose dispensing of drugs lead to improved medication? Norsk Farmaceutisk Tidsskrift. 2012;4:9-13

34. Tommelein E, Mehuys E, Petrovic M, Somers A, Colin P, Boussery K Potentially inappropriate prescribing in community-dwelling older people across Europe: a systematic literature review. Eur J Clin Pharmacol. 2015; 71(12):1415-27.

35. O'mahony D, O'sullivan D, Byrne S, O'connor MN, Ryan C, Gallagher P. STOPP/START criteria for potentially inappropriate prescribing in older people: version 2. Age Ageing. 2015:44(2):213-8.

36. The Norwegian Directorate of Health (2015) [Guide to medication reviews].

37. Rosholm J-U, Bjerrum L, Hallas J, Worm J, Gram LF. Polypharmacy and the risk of drug-drug interactions among Danish elderly. A prescription database study. Dan Med Bull. 1998;45(2):210-3.

38. Hammar T, Lidstrom B, Petersson G, Gustafson Y, Eiermann B. Potential drug-related problems detected by electronic expert support system: physicians' views on clinical relevance. Int J Clin Pharm. 2015:37(5):941-8. https://doi.org/10.1007/s11096-015-0146-8.

39. Johnell K, Klarin I. The relationship between number of drugs and potential drug-drug interactions in the elderly: a study of over 600,000 elderly patients from the Swedish prescribed drug register. Drug Saf. 2007;30(10):911-8.

40. Johnell K, Weitoft GR, Fastbom J. Sex differences in inappropriate drug use: a register-based study of over 600,000 older people. Ann Pharmacother. 2009;43(7-8):1233-8 
41. Carey IM, De Wilde S, Harris T, Victor C, Richards N, Hilton SR, Cook DG. What factors predict potentially inappropriate primary care prescribing in older people? Drugs Aging. 2008;25(8):693-706.

42. The Norwegian Institute of Public Health (2011) The Norwegian Prescription Database. http://www.norpd.no/.

43. Furu $\mathrm{K}$, Wettermark $\mathrm{B}$, Andersen M, Martikainen JE, Almarsdottir AB, Sorensen HT. The Nordic countries as a cohort for pharmacoepidemiological research. Basic Clin Pharmacol Toxicol. 2010; 106(2):86-94. https://doi.org/10.1111/j.1742-7843.2009.00494.x.

44. Wang-Hansen MS, Wyller TB, Hvidsten LT, Kersten H. Can screening tools for potentially inappropriate prescriptions in older adults prevent serious adverse drug events? Eur J Clin Pharmacol. 2019;75:627-37. https://doi.org/ 10.1007/s00228-019-02624-1.

\section{Publisher's Note}

Springer Nature remains neutral with regard to jurisdictional claims in published maps and institutional affiliations.

Ready to submit your research? Choose BMC and benefit from:

- fast, convenient online submission

- thorough peer review by experienced researchers in your field

- rapid publication on acceptance

- support for research data, including large and complex data types

- gold Open Access which fosters wider collaboration and increased citations

- maximum visibility for your research: over $100 \mathrm{M}$ website views per year

At $\mathrm{BMC}$, research is always in progress.

Learn more biomedcentral.com/submissions 